\title{
Estimation of Additional Downward Radiation from Aerosols over Large Cities
}

\author{
By Giichi Yamamoto \\ Geophysical Inslitute, Tōhoku University, Sendai, Japan \\ (Manuscript received 31 May 1957)
}

\section{Introduction}

Atmospheric pollution over large cities has been increasing rapidly in recent years, and some meteorologists believe that a downward radiation from aerosrls plays a rôle of preventing nocturnal cooling in large cities. In fact the preserce of an additional downward radiation whose origin is other than $\mathrm{H}_{2} \mathrm{O}$ and $\mathrm{CO}_{2}$ was suggested by Robinson [1] by the analysis of radiation measurements made at Kew Observatory. However, later Yamomoto and Sasamori [2] showed that the observed values of downward radiation at Sendai were in good agreement with the values computed by the Yamamoto radiation chart which treats $\mathrm{H}_{2} \mathrm{O}$ and $\mathrm{CO}_{2}$ as radiator. They also showed that isothermal emissivity can not be determined uniquely from radiation measurements in the atmosphere by the Robinson or Brooks [3] method. that is, higher values of isothermal emissivity were obtained in cases of inversion than in cases of no inversion for the same amount of $\mathrm{H}_{2} \mathrm{O}$ and $\mathrm{CO}_{2}$. In spite of our investigation, as Sendai is a middle sized city without appreciable sources of air pollution, there still remains a question, whether the atmospheric pollution over large cities is really ineffective to long wave radiation or not. In the present paper the author has examined the problem from an entirely different point of view.

\section{Estimation of additional downward radiation from aerosols}

First we shall consider the depletion of solar radiation through scattering by air molecules, water vapour and aerosols. According to Linke [4] the intensity $I$ of the direct solar radiation transmitted through the cloudless atmosphere is given by

$$
I=I_{0} \exp (-s \tau m),
$$

where $I_{0}$ is the solar constant, $m$ the air mass. measured in terms of the zenith path as unity, $s$ the extinction coefficient averaged over wave length of the pure air of a unit air mass, and $\tau$ the turbidity factor. If we write (1) in the following torm;

$$
I=I_{0} \exp \left\{-\left(s+s^{\prime}\right) m\right\}
$$

then $s^{\prime}$ means the extinction coefficient of water vapour and aerosols in a unit air mass. Here by the term aerosols we mean all the impurities in the air involving condensation nuclei, smokes and dust particles. From (1) and (2) we have

$$
s^{\prime}=s(\tau-1)
$$

By some investigators the extinction coefficient $s^{\prime}$ is further separated into two parts, one due to water vapour and the other to. dust. For instance, Fowle [5] found that the extinction coefficient of water vapour determined from observations was 64 times. larger than that would arise trom molecular scattering by $\mathrm{H}_{2} \mathrm{O}$ molecules. Later the value 64 was reduced to 5 by Tien Kiu [6]. As regard to the explanation of these results, it is supposed that at least a part of the $\mathrm{H}_{2} \mathrm{O}$ molecules occurs in the form of small droplets. or clusters of molecules [7]. In the present research we will include such polymerized molecules or small droplets into the category of aerosols and will neglect the extinction due to pure water vapour molecules. In 
other words we assume the extinction coefficient $s^{\prime}$ as due to aerosols alone.

According to Kimball [8] the intensity of direct solar radiation through the dry and dustless air of a unit path length $(m=1)$ is given by $I / I_{0}=\exp (-s)=0.914$. From this we can derive the value of $s$ to be 0.09 . Next the value of $\tau$ for representative, clear and contaminated atmospheres in Japan are as shown in Table 1 . As can be seen in the

Table 1. The annual mean values of $\tau$. [9]

\begin{tabular}{l|c|c|c}
\hline \multicolumn{1}{c|}{ Station } & Longitude & Latitude & $\tau$ \\
\hline Tokyo & $139^{\circ} 46^{\prime} \mathrm{E}$ & $35^{\circ} 41^{\prime} \mathrm{N}$ & 4.27 \\
Osaka & $135^{\circ} 30^{\prime} \mathrm{E}$ & $34^{\circ} 39^{\prime} \mathrm{N}$ & 4.46 \\
Shimizu & $133^{\circ} 01^{\prime} \mathrm{E}$ & $32^{\circ} 43^{\prime} \mathrm{N}$ & 2.82 \\
Kakioka & $140^{\circ} 11^{\prime} \mathrm{E}$ & $36^{\circ} 14^{\prime} \mathrm{N}$ & 2.83 \\
\hline
\end{tabular}

table, the Osaka atmosphere is most contaminated in Japan. From (3) the value of $s^{\prime}$ for the Osaka atmosphere can be obtained to be 0.312 .

Now let the total quantity of aerosols in a unit air mass be $x\left(\mathrm{~g} \mathrm{~cm}^{-2}\right)$, then we have

$$
s^{\prime}=t x
$$

where $t\left(\mathrm{~g}^{-1} \mathrm{~cm}^{2}\right)$ is the scattering coefficient of aerosols per unit mass with unit cross section. If the value of $t$ is known we can estimate the total quantity of aerosols over Osaka from (4). Unfortunately the value of $t$ for aerosols is not yet known, owing to the difficulty of measuring the amount of aerosols in an open air. Several years ago Yamamato and Saito [10] measured the transmissivity of visible and infrared radiations through smokes in the laboratory. In this case we were able to measure the amount of smoke particles. The mean value of the mass scattering coefficient for several smokes was $7440 \mathrm{~g}^{-1} \mathrm{~cm}^{2}$ in our experiment. With the use of this value we can derive from (4) the total quantity of aerosols over Osaka to be $x=4.19 \times 10^{-5} \mathrm{~g} \mathrm{~cm}^{-2}$.

Now the mean absorption coefficient of smokes over infrared region measured in the above quoted experiment by Yamamoto and Saito [10] is $450 \mathrm{~g}^{-1} \mathrm{~cm}^{-2}$. Using this value the transmission for slab $\tau_{f}$ by the aerosols over Osaka is approximately given by

$$
\tau_{f}=\exp \left(-1.66 \times 450 \times 4.19 \times 10^{-5}\right)=0.969 \text {, }
$$

where the numerical factor 1.66 is due to Elsasser [11]. Equation (5) means that the isothermal atmosphere containing aerosols as much as the Osaka atmosphere absorbs only 3 per cent of the incident radiation. Because of the smallness of the absorption by aerosols an approximate estimation will be enough as to the additional downward radiation due to aerosols. If we use the Yamamoto radiation chart [12] the downward radiation $D$ at the surface by $\mathrm{H}_{2} \mathrm{O}$ and $\mathrm{CO}_{2}$ in the atmosphere is given by

$$
D=B\left(T_{0}\right)-\int_{0}^{B\left(T_{o}\right)}\left\{\overline{\left.\tau_{f}(u, T)-\Delta \tau_{f}\left(u, u_{c o_{2}}\right)\right\}} d B,\right.
$$

where $B\left(T_{0}\right)$ is the black body radiation at the surface temperature $T_{0}, u, u_{c o_{2}}$ the optical paths of $\mathrm{H}_{2} \mathrm{O}$ and $\mathrm{CO}_{2}$ respectively and $\left.\overline{\tau_{f}(u, T)-\Delta \tau_{f}\left(u, u c o_{2}\right.}\right)$ the mean transmission over wave length by $\mathrm{H}_{2} \mathrm{O}$ and $\mathrm{CO}_{2}$. The downward radiation $D^{\prime}$ at the surface by $\mathrm{H}_{2} \mathrm{O}, \mathrm{CO}_{2}$ and aerosols is approximately given by

$$
\begin{aligned}
D^{\prime}=B\left(T_{0}\right) & -\int_{0}^{B\left(T_{o}\right)} \frac{\left.1 \tau_{f}(u, T)-\Delta \tau_{f}\left(u, u c o_{2}\right)\right\}}{} \\
& \times \tau_{f}\left(u_{\text {aero } o}\right) d B
\end{aligned}
$$

where $\tau_{f}\left(u_{a \text { ero }}\right)$ is the transmission by aerosols whose value is given above.

The annual mean temerature and humidity in Osaka are $15.3^{\circ} \mathrm{C}$ and $73 \%$, but their vertical distribution is not known, at least, to the author. According to London [13], however, the temperature and humidity at $30^{\circ}-40^{\circ} \mathrm{N}$ belt during March are $13.0^{\circ} \mathrm{C}$ and $71 \%$ at the surface and the vertical distribution of them is known in detail. Ignoring the minor differences we will assume that the data obtained by London can be applied to the Osaka atmosphere. Then the downward radiation by $\mathrm{H}_{2} \mathrm{O}$ and $\mathrm{CO}_{2}$ computed by the Yamamoto chart is $0.414 \mathrm{cal} \mathrm{cm}^{-2} \mathrm{~min}^{-1}$, and the additional downward radiation by aerosols over Osaka is given by the difference of

be:

rac

th:

$\cos$

dei

dia

3. 
of (7) and (6) to be $0.004 \mathrm{cal} \mathrm{cm}^{-2} \mathrm{~min}^{-1}$, being less than one per cent of the downward radiation by $\mathrm{H}_{2} \mathrm{O}$ and $\mathrm{CO}_{2}$. The result of this computation suggests that, even in the contaminated air such as Osaka's the direct detection of the presence of the additional radiation by aerosols from observations of radiation will be difficult, owing to the expected errors of observations of radiation and of humidity in the free atmosphere.

\section{Discussion on heat budget of large cities}

Owing to a large extinction coefficient for visible light and a small absorption coefficient for infrared radiation of aerosols, the net effect of aerosols to solar and terrestrial radiations is to diminish the amount of radiation received at the surface of large cities and to cool the surface and lower layers in comparison with those of country sides. This is best illustrated in Table 2, in which the mean daily amounts of insolation received by 1 $\mathrm{cm}^{2}$ of the horizontal surface at several stations in Japan are shown. Obviously the amounts received in large cities are much less than those received at small cities. In comparison with this large difference, the difference of the daily amounts of additional

Table 2 The mean daily amounts over five days of insolation during February and August, 1953 [14]

Unit : cal $\mathrm{cm}^{-2} \mathrm{day}^{-1}$

\begin{tabular}{|c|c|c|c|c|}
\hline Date & Osaka & \begin{tabular}{|c|} 
Kochi \\
$133^{\circ} 33^{\prime} \mathrm{E}$ \\
$33^{\circ} 34^{\prime} \mathrm{N}$
\end{tabular} & Tokyo & $\begin{array}{c}\text { Utsunomiya } \\
139^{\circ} 52^{\prime} \mathrm{E} \\
36^{\circ} 33^{\prime} \mathrm{N} \\
\end{array}$ \\
\hline $\begin{array}{l}\text { 31, Jan. - 4, Feb. } \\
\text { 5,Feb. - 9, Feb. } \\
\text { 10,Feb. - 14, Feb. } \\
\text { 15,Feb. - 19, Feb. } \\
\text { 20,Feb. - 24, Feb. } \\
\text { 25,Feb.-1, March } \\
\text { Mean }\end{array}$ & $\begin{array}{l}178 \\
291 \\
226 \\
213 \\
218 \\
203 \\
221\end{array}$ & $\begin{array}{l}310 \\
412 \\
332 \\
330 \\
341 \\
265 \\
332\end{array}$ & $\begin{array}{l}200 \\
240 \\
164 \\
250 \\
227 \\
179 \\
210\end{array}$ & $\begin{array}{l}259 \\
278 \\
195 \\
293 \\
295 \\
239 \\
260\end{array}$ \\
\hline $\begin{array}{l}\text { 30,July. - 3, Aug. } \\
\text { 4,Aug. - 8, Aug. } \\
\text { 9,Aug. -13, Aug. } \\
\text { 14,Aug. -18, Aug. } \\
\text { 19,Aug. -23, Aug. } \\
\text { 24,Aug. -28, Aug. } \\
\text { Mean }\end{array}$ & $\begin{array}{l}383 \\
289 \\
314 \\
315 \\
321 \\
221 \\
307\end{array}$ & $\begin{array}{l}495 \\
446 \\
362 \\
420 \\
515 \\
364 \\
432\end{array}$ & $\begin{array}{l}327 \\
193 \\
338 \\
209 \\
282 \\
126 \\
246\end{array}$ & $\begin{array}{l}403 \\
354 \\
333 \\
275 \\
338 \\
216 \\
320\end{array}$ \\
\hline
\end{tabular}

radiation received at large cities and small cities would be negligible, being probably of the order of a few calories per day per $\mathrm{cm}^{2}$.

In spite of the large radiation deficit in large cities it is generally believed that the climate of large cities is warmer than that of suburbs or countries. Taking the circumstance for granted, one of the important causes of it would be, of course, the heat produced from industrial and domestic furnaces in large cities. For example, Osaka and its circumferential cities consume about 10 million tons of coal per year. Assuming one gramme of coal to produced 8000 calories of heat and the area of Osaka and its circumferential cities to be $4 \times 10^{12} \mathrm{~cm}^{2}$, the mean production of heat by coal is about 55 cal $\mathrm{cm}^{-2}$ day $^{-1}$. Although the value seems insufficient to compensate the radiation deficit in large cities, the inhabitants of Osaka use charcoal, petroleum and electric power, etc., other than coal, so that the total amount of heat produced artificially may be sufficient for the warming of air in large cities.

Besides, several meteorological factors favorable to the temperature rise in large cities are considered. One of them is the diminution of evaporation in large cities as already pointed out by Geiger [15]. In large cities a considerable part of precipitation will flow into a drainage system and will be ineffective to cooling of the surface by evaporation. If we assume that a half of the amount of precipitation in large cities is ineffective to evaporation, while all the amount is effective in the country sides, the difference of heat loss due to evaporation between Osaka, whose annual precipitation is $1274 \mathrm{~mm}$, and its suburbs is about $103 \mathrm{cal} \mathrm{cm}^{-2} \mathrm{day}^{-1}$, which is comparable to the radiation deficit in Osaka.

The difference of the surface condition between large cities and the suburbs further affects the microclimatology through the difference of cooling by long wave radiation. According to Falckenberg [16] the blackness to long wave radiation of the surface of sand 
is about 89 per cent. The blackness of large cities whose surface is mainly made of concrete, brick, tile, etc., will be of the same order as that of sand. Whereas the blackness of the rural districts of Japan, the greater part of which is rice fields, will be about 95 per cent or more. If we assume these values of the surface blackness and the surface temperature of both the city and its suburb to be $15^{\circ} \mathrm{C}$, the difference of surface cooling by long wave radiation will amount to about 49 cal $\mathrm{cm}^{-2}$ day $^{-1}$.
Lastly the effect of city fog will be mentioned. Although aerosols themselves are nearly ineffective in preventing the nocturnal cooling as described above, they favour the formation of fog which prevents the cooling of the surface and lower layers of the atmosphere most effectively.

These meteorological factors will not necessarily act simultaneously or continuously, but we cannot deny that these will be as important in modifying the city climate as the heat produced artificially.

\section{References}

1) Robinson, G. D. 1947, 1950: Quart. J.r. Meteor. Soc., 73, 127 ibid., 76, 37. -2) Yamamoto, G. and T. Sasamori. 1954: Sci. Rep. Tohoku Univ., Ser. 5, Geophysics, 6, 19 -3) Brooks, F. A. 1940: Inst. Pap. Phys. Ocean. Met., Cambridge, Mass., 8, No. 2. -4) Linke, F. 1942: Handbuch der Geophysik, VIII, Berlin-Zehleudorf, Verlag von Gebrüder Borntraeger. -5) Fowle, F. E. 1913: Astrophys. J. 38, 392. -6) Tien Kiu 1938: J. de Phys., 9 297. -7) Van de Hulst, H. C. 1951 : The Atmosphere of the Earth and Planets, edited by G. P. Kuiper, p. 49. -8) Kimball, H. H. 1931: Nat. Res. Coun., Nat. Acad. Sci., Washington, D. C., -9) Kitaoka, T., and Y. Matuoka 1947 : Geoph. Mag., 15, 5. -10) Yamamoto, G. and T. Saito 1954: Sci. Rep. Tohoku Univ., Ser. 5, Geophysics, 6, 32 -11) Elsasser, W. M. 1942: Harvard Meteor. Studies, No. 6. -12) Yamamoto, G. 1952: Sci. Rep. Tohoku Univ. Ser. 5, Geophysics, 4. 11. -13) London, J. 1950, 1951: U.S. Air Force Cambridge Res. Lab. Progress Rep. 131.02 \& 131.03 ibid 131. 05. - 14) 1955: Actinometeric Bulletin. Central Meteorological Observatory of Japan. -15) Geiger, R. 1951: Compendium of Meteorology, Boston, Mass., p. 993. -16) Falckenberg, Von G. 1928: Meteor. Zeit., 45, 334. 